\title{
ArogyaKshema: COVID 19 Infection Self Assessment Test App
}

\author{
C.R.S. Kumar \\ Dept of Computer Science and \\ Engineering \\ Defence Institute of Advanced \\ Technology (DIAT) \\ Pune 411025 India
}

\author{
Pradeep Pai T. \\ Dept of Computer Science and \\ Engineering \\ Defence Institute of Advanced \\ Technology (DIAT) \\ Pune 411025 India
}

\author{
Kunal Pal \\ Dept of Computer Science and \\ Engineering \\ Defence Institute of Advanced \\ Technology (DIAT) \\ Pune 411025 India
}

\begin{abstract}
Arogya-Kshema is the COVID 19 Infection Self-Assessment Test App (Android). The Android app is made available using Google Server and Google play store for general public. The test covers all the symptoms of the COVID-19 Infection. The test has been designed in consultation with Medical doctors and experts. The COVID -19 infection symptoms tested are as per the guidelines of ICMR and WHO. There are 13 Multiple Choice questions which the user needs to answer. The test results are provided as different colour codes to prioritize the patients for further Medical consultations. The green code is for the person who is free from the COVID-19 Infection. Blue and Red code indicates suspected infection and the user is advised to consult the doctor at the earliest. The test is made available in Hindi and English and many other languages (Malayalam, Tamil, Telugu, Kannada, Marathi, Bengali, Japanese, Spanish, Italian, German and Russian)
\end{abstract}

\section{General Terms}

COVID-19, android, self-test application, social vaccine, algorithm

\section{Keywords}

ArogyaKshema, COVID-19, android, self-test application, social vaccine, algorithm

\section{INTRODUCTION}

COVID-19 stands for Corona Virus Disease of 2019[5]. The COVID pandemic started in December 2019 in Wuhan, China. It has been spreading world-wide and resulted in Global infection of more than 13 million people and death of more than half a million persons [1] based on WHO Dashboard as on 17th July 2020. The highly infectious COVID-19 has resulted in many lock downs and serious distress. There are many biological vaccines under development [4]. However, till the biological vaccines are developed, in order to control and contain the spread of COVID-19 infections, the only solution is Social Vaccine. The Social vaccine is for new normal of social and behavioral modalities. Some of the measures of social vaccines are Social distancing, wearing masks, Sanitisation etc.

The symptoms of the patients can be analyzed and decisions whether they are COVID-19 infected can be arrived at by medical experts. However, there may be cases of mild/moderate infection due to which clear decisions are difficult. Also, there are many diseases with overlapping symptoms which can make it difficult to arrive at a clear-cut diagnosis. In this regard, the confirmation may be obtained through biological testing. Due to large number of COVID-
19 Infection cases, it will be a burden on medical facilities to test all the people. This is where Self-Assessment Test plays an important role.

The persons who are suspecting that they have COVID-19 infections need not rush to hospitals. Rather, they can use the ArogyaKshema App which is made available free for Android phones. They can run the app and enter their choices for the questions posed by the app. The app will generate an advice which can help the users in making a decision to consult the Doctor. The ArogyaKshema App thus helps prioritize the patients and thus helps reduce the unnecessary rush at Hospitals. Also, biological tests which are administered in hospitals and diagnostic labs, are expensive and time consuming. ArogyaKshema app will thus save cost and effort significantly.

This paper is structured as follows: In the next section, the current practices in COVID-19 testing are discussed. In the section 3, ArogyaKshema architecture and design are presented along with its components. In section 4, implementation and usage of ArogyaKshema App are discussed. The summary and conclusions are presented in section 5 .

\section{COVID-19 TESTING}

The COVID-19 global pandemic requires that extensive testing need to be done to find people who have been infected with corona virus. Such infected persons need to be isolated and medical treatment should be provided at the earliest to contain and control the spread of COVID-19 infection. The best strategy in this regard is testing. There are two approaches of testing:
A. Biological testing using samples collected from individuals (Nasopharyngeal Swab)
B. Symptom based testing

The biological testing using samples collected through Nasopharyngeal Swabs is through two approaches i.e. RAT (Rapid Antigen Test) and RT-PCR (Reverse Transcription Polymerase Chain Reaction). The following table shows the comparison of RAT and RT-PCR: 
Table 1: Test Comparison (Source TOI July 31st 2020)

\begin{tabular}{|c|c|c|}
\hline $\begin{array}{c}\text { Sl } \\
\text { No }\end{array}$ & RAT & RT-PCR \\
\hline 1 & $\begin{array}{c}\text { Time taken is 15-30 } \\
\text { minutes }\end{array}$ & Time taken is 3-4 hours \\
\hline 2 & Cost is around Rs 450 & Cost is around Rs 2500 \\
\hline 3 & $\begin{array}{c}\text { Result is made visible } \\
\text { to Eye }\end{array}$ & $\begin{array}{c}\text { Result is read by the } \\
\text { machine }\end{array}$ \\
\hline 4 & $\begin{array}{c}\text { Accuracy is low with } \\
\text { very high False } \\
\text { Negative }\end{array}$ & $\begin{array}{c}\text { Accuracy is very high and } \\
\text { RT-PCR is considered gold } \\
\text { standard for detection of } \\
\text { SARs_COV2 virus }\end{array}$ \\
\hline
\end{tabular}

The following table for testing statistics shows that the large number of testing to be carried out. In India, more than 20 million tests are performed as on 3rd August 2020 with around 6 lakh tests in a day. The significant effort and cost involved in the massive scale of testing shows that alternate methods of cost effective and high-speed testing are the need of the hour.

Table 2: COVID-19 testing Statistics (source [16])

\begin{tabular}{|c|c|c|c|c|c|c|c|}
\hline Country & Date & Tested & Units & $\begin{array}{c}\text { Confirmed } \\
\text { (cases) }\end{array}$ & \% & $\begin{array}{c}\text { Tested /million } \\
\text { people }\end{array}$ & $\begin{array}{c}\text { Confirmed / million } \\
\text { people }\end{array}$ \\
\hline China & 22 June & $90,410,000$ & samples & 90,083 & 0.09 & 62,814 & 63 \\
\hline USA & 3 August & $57,543,852$ & samples & $4,694,126$ & 8.2 & 173,856 & 14,182 \\
\hline Russia & 29 July & $27,857,850$ & samples & 834,499 & 3.0 & 189,838 & 15,121 \\
\hline India & 4 August & $20,864,750$ & samples & $1,855,745$ & 8.9 & 5,687 & 1,345 \\
\hline UK & 2 August & $12,250,937$ & samples & 305,623 & 2.5 & 181,372 & 4,525 \\
\hline
\end{tabular}

The major symptoms of the COVID-19 infection are published by ICMR and WHO [1,12] and are listed in the following table. As the COVID-19 Infection is being studied, the list of symptoms may be updated. The new symptoms of Loss of Tase/Smell were recently updated by ICMR. The majority of the symptoms require that the individual infected should observe the symptoms and communicate then to healthcare worker or Medical Doctor.

Table 3: Symptoms and indicators

\begin{tabular}{|c|c|c|}
\hline $\begin{array}{c}\text { Sl } \\
\text { No }\end{array}$ & Symptom & Indicator/Remarks \\
\hline 1 & Fever & Thermometer \\
\hline 2 & Dry Cough & Feedback \\
\hline 3 & Shortness of Breath & Feedback \\
\hline 4 & Sore Throat & Feedback \\
\hline 5 & Headache & Feedback \\
\hline 6 & Fatigue & Feedback \\
\hline 7 & Digestive: & Feedback \\
& Diarrhea/Nausea/Vomiting & Feedback \\
\hline 8 & Loss of Taste/Smell & \\
\hline
\end{tabular}

There are also asymptotic COVID-19 infections which sometimes can be detected by use of Pulse Oximeter. It can be observed that Thermometer or Pulse-Oximeter, while being useful in diagnosing the COVID-19, they are not sufficient.
The confirmation can be obtained by the advanced testing using RAT or RT-PCR.

\section{AROGYAKSHEMA:}

\section{ARCHITECTURE AND DESIGN}

ArogyaKshema mobile app is developed for the android platform and provides a COVID-19 self-assessment test kit to the end user. The mobile application has been designed with emphasis on user and data privacy. ArogyaKshema mobile app does not collect, store or share information shared by user as part of the self-assessment test. A central design point of the Android security architecture is that no app, by default, has permission to perform any operations that would adversely impact other apps, the operating system, or the user. This includes reading or writing the user's private data (such as contacts or emails), reading or writing another app's files, performing network access, keeping the device awake, and so on. ArogyaKshema app runs on safest possible protection level with access to only isolated application-level features, with minimal risk to other applications, the system, or the user. The user also has the option to review these permissions before and after installation. In other words, ArogyaKshema app does not require or request access to user/system sensitive information like file explorer access, camera access, SMS/Email access, contact access, Bluetooth / WIFI access or even network access. 


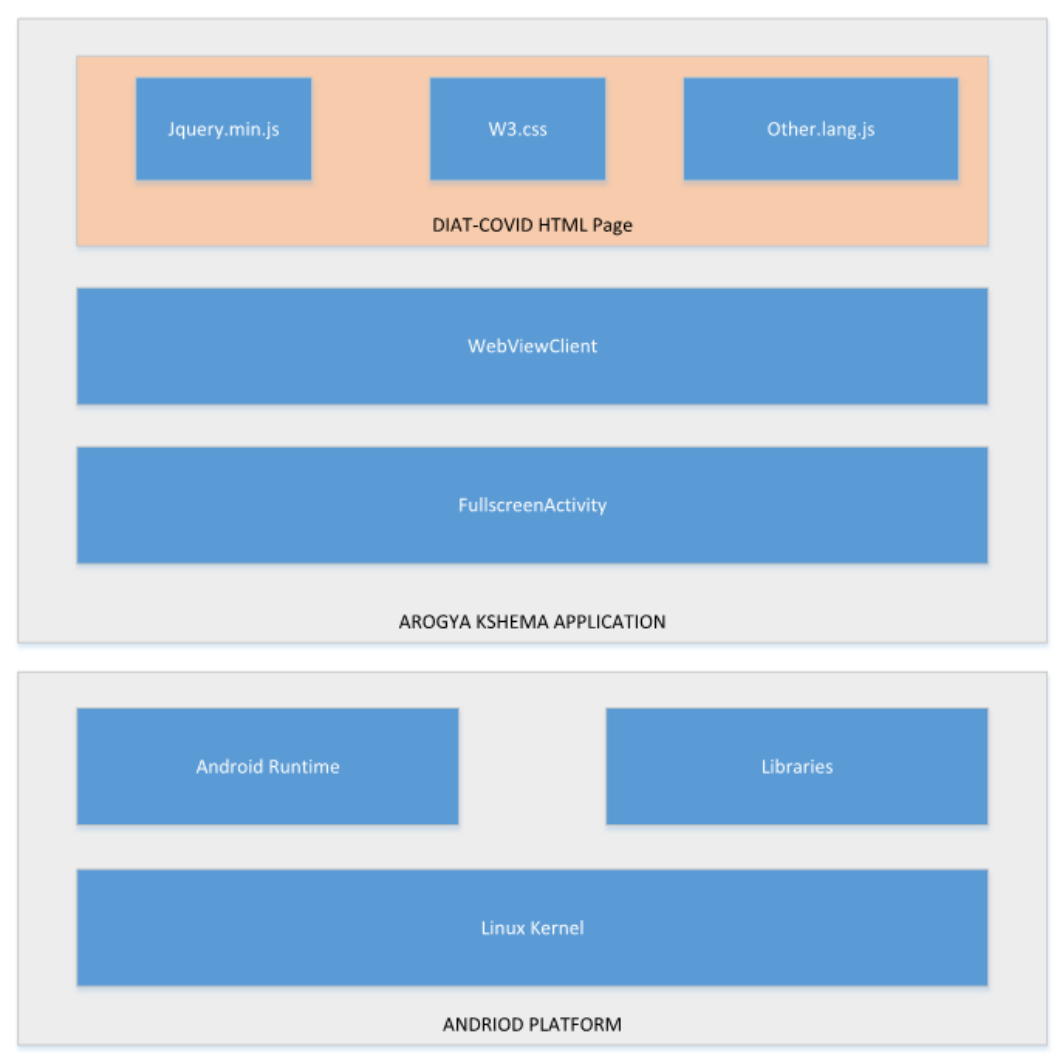

Figure 1: ArogyaKshema Architecture

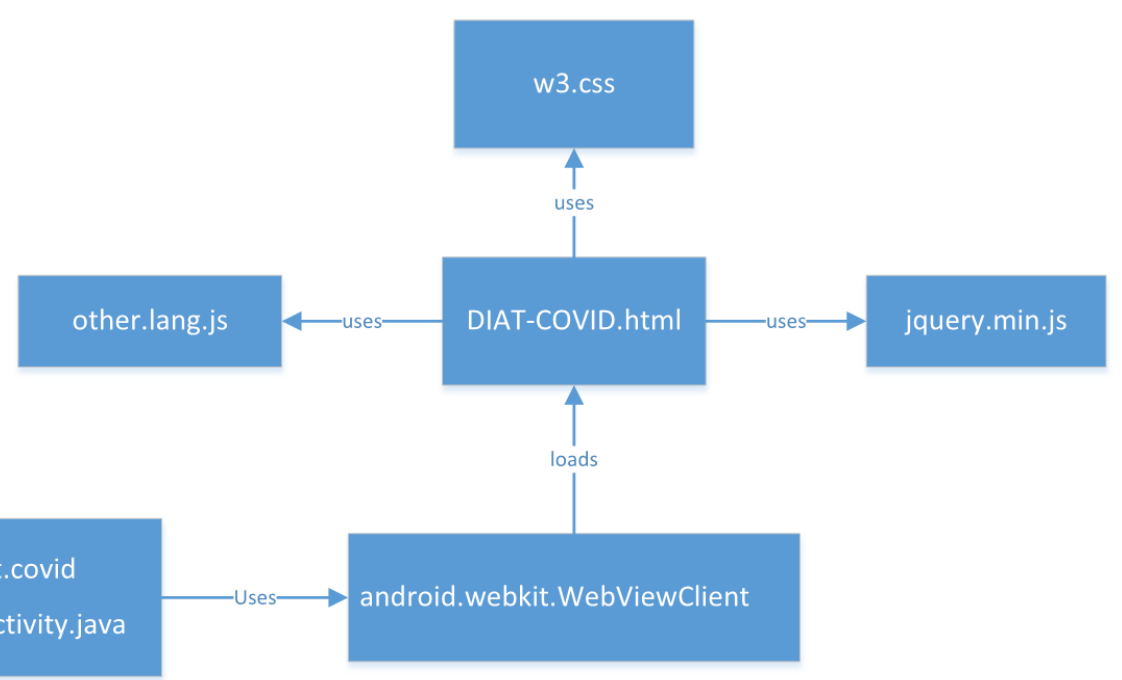

Figure 2: Components and interaction in ArogyaKshema App

\section{AROGYAKSHEMA:}

\section{IMPLEMENTATION AND USAGE}

ArogyaKshema app has been developed using latest version of Android Studio. Packaging and code structure details:

Package name : in.ac.diat.covid

Class name : FullscreenActivity.javaHtml

Source name : DIAT-COVID.html

FullscreenActivity.java java class of the package in.ac.diat.covid is the main activity class that renders and manages the app activity. It uses the android webkit's WebViewClient that allows the display of web content as part of the activity layout. DIAT-COVID.html is a custom developed HTML application. It is a single page $\mathrm{html} /$ javascript/css based application which is built to be mobile responsive and provides a multi-lingual experience to the user. It uses the following JavaScript and css files to provide the desired user experience.

A. W3.CSS: W3.CSS is a modern CSS framework with support for desktop, tablet, and mobile design by default. It is smaller and faster than similar CSS frameworks. It is designed to be a high-quality alternative to Bootstrap. It is designed to be smaller, faster, easier to learn, and easier to use. It was also designed to be independent of jQuery or any other JavaScript library. 
B. jquery.min.js: jQuery is a fast, small, and featurerich JavaScript library. It makes things like HTML document traversal and manipulation, event handling, animation, and Ajax much simpler with an easy-to-use API that works across a multitude of browsers. With a combination of versatility and extensibility, jQuery has changed the way that millions of people write JavaScript.

C. other.lang.js is a custom developed javascript file that provides the app with multilingual capability.

\subsection{Decision Matrix}

Arogyakshama app follows the following decision matrix. Every option of every question is assigned a weightage and final score is calculated as an aggregate sum of the weights of the chosen options. The final score is then compared with the threshold values to determine the suggesstion. The questions and weights assgined to each individual option of each question and also the thresholds of the final score is depicted as below.

\begin{tabular}{|c|c|c|c|c|c|}
\hline No & Question & & Response fror & $n$ user & \\
\hline 1 & $\begin{array}{l}\text { Do you have any International Travel } \\
\text { History/Contact History with } \\
\text { Confirmed COVID } 19 \text { case? }\end{array}$ & $\begin{array}{l}\text { No International } \\
\text { Travel } \\
\text { History/Contact }\end{array}$ & $\begin{array}{l}\text { Travel } \\
\text { History/Contact } \\
\text { History more than } 14\end{array}$ & $\begin{array}{l}\text { Travel } \\
\text { History/Contact } \\
\text { History less than }\end{array}$ & $\begin{array}{l}\text { Direct Contact } \\
\text { with Confirmed } \\
\text { COVID } 19 \text { case }\end{array}$ \\
\hline 2 & Do you have fever? & No & Yes & & \\
\hline 3 & Do you have any breathing difficulty? & No & Yes & & \\
\hline 4 & Do you have any pain in the body? & No & Mild & Moderate & Severe \\
\hline 5 & Are you having any fatigue/weakness? & No & Mild & Moderate & Severe \\
\hline 6 & Do you have a sore throat? & No & Yes & & \\
\hline 7 & Do you have a dry cough? & No & Yes & & \\
\hline 8 & $\begin{array}{l}\text { Do you have diarrhoea or Nausea / } \\
\text { Vomiting in last } 24 \text { hours? }\end{array}$ & No & Yes & & \\
\hline 9 & $\begin{array}{l}\text { medical conditions? - Hypertension, } \\
\text { Diabetes Mellitus, Obesity, Heart } \\
\text { Disease, COPD / Asthma / Chronic } \\
\text { Lung disease, Chronic Liver Disease or } \\
\text { Chronic Kidney disease, Malignancy } \\
\text { (Cancer), are you Currently on Steroid } \\
\text { therapy }\end{array}$ & No & Yes & & \\
\hline 10 & $\begin{array}{l}\text { How is your health status in the last } \\
48 \mathrm{hrs} \text { ? }\end{array}$ & Improved & No Change & Worsened & Worsened a lot \\
\hline 11 & Your age? & age less than 10 & age $10-60$ Years old & age More than & \\
\hline 12 & Do you have Loss of Taste sensation? & No & Yes & & \\
\hline 13 & Do you have loss of smell sensation? & No & Yes & & \\
\hline
\end{tabular}

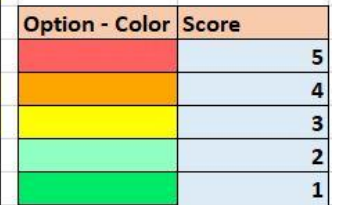

Figure 3: Decision Matrix for ArogyaKshema App

The ArogyaKshema app is useful for COVID 19 Infection Self-Assessment Test. The app can be installed on any Android Phones. The app is user friendly and does not require extensive training. The app is multi-lingual and supports Indian and Foreign languages. The app has been developed in consultation with medical doctors and is based on the guidelines issued by ICMR and WHO.

ArogyaKshema app is standalone app developed using Android Studio. The app has 13 Multiple Choice questions which are designed to collect the user's symptoms and health conditions. The app generates diagnostic messages with colour codes which assist the user in availing appropriate medical advise. The app is useful for individuals, doctors, medical staff, health care workers in the current COVID 19 Pandemic. The app is easy to use, interactive, timely, efficient and well designed, highly secure. The app is certified by google and published on google play store. The app is provided free of cost and supports almost all android phones.

\subsection{Installation}

Download the ArogyaKshema.apk file from Link:

http://14.139.111.180/ArogyaKshema/Arogyakshema.html. On double clicking the apk file, the installation will start. It may take couple of minutes to install the app. The App is a published on the Google Play store. The QR code and link of Google play store are as follows: https://play.google.com/store/apps/details?id=in.ac.diat.covid

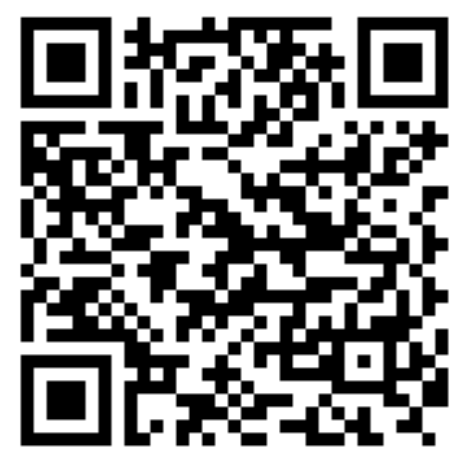

Figure 4: QR Code for the Google Play listing of ArogyaKshema App

\subsection{App Navigation}

1. On double clicking on the icon, the app opens up. The first displays the drop-down menu with various language choices:

a. Indian Languages: English, Hindi, Marathi, Kannada, Telugu, Tamil, Malayalam

b. Foreign Languages: Japanese, German, Italian, Spanish, Russian Default selection is English.

2. The user is required to select the language and click Enter button.( Fig1) 

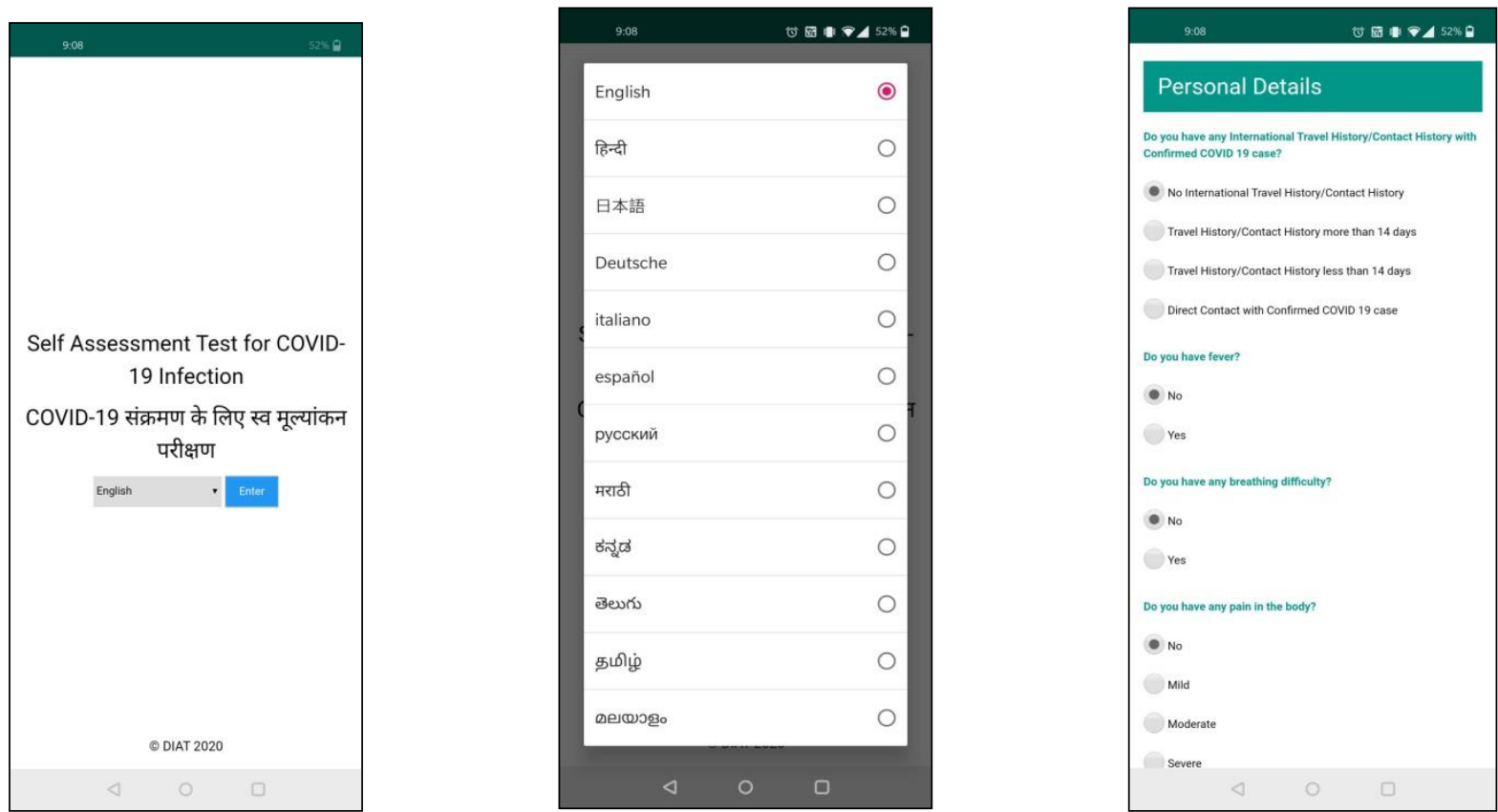

Figure 5: Mobile Phone Screen shots of Home Screen, Language selection Menu, Assessment Test MCQs

3. The Self-assessment test begins with the questionnaire:

a. There are thirteen questions

b. 8 questions have Yes/No option.

c. 5 questions have multiple options

d. Users can choose one of the answers by touching on the answer (touch screen mobile)

e. The default answers for normal persons without infection

4. The user can submit the answers by selecting Submit Button.
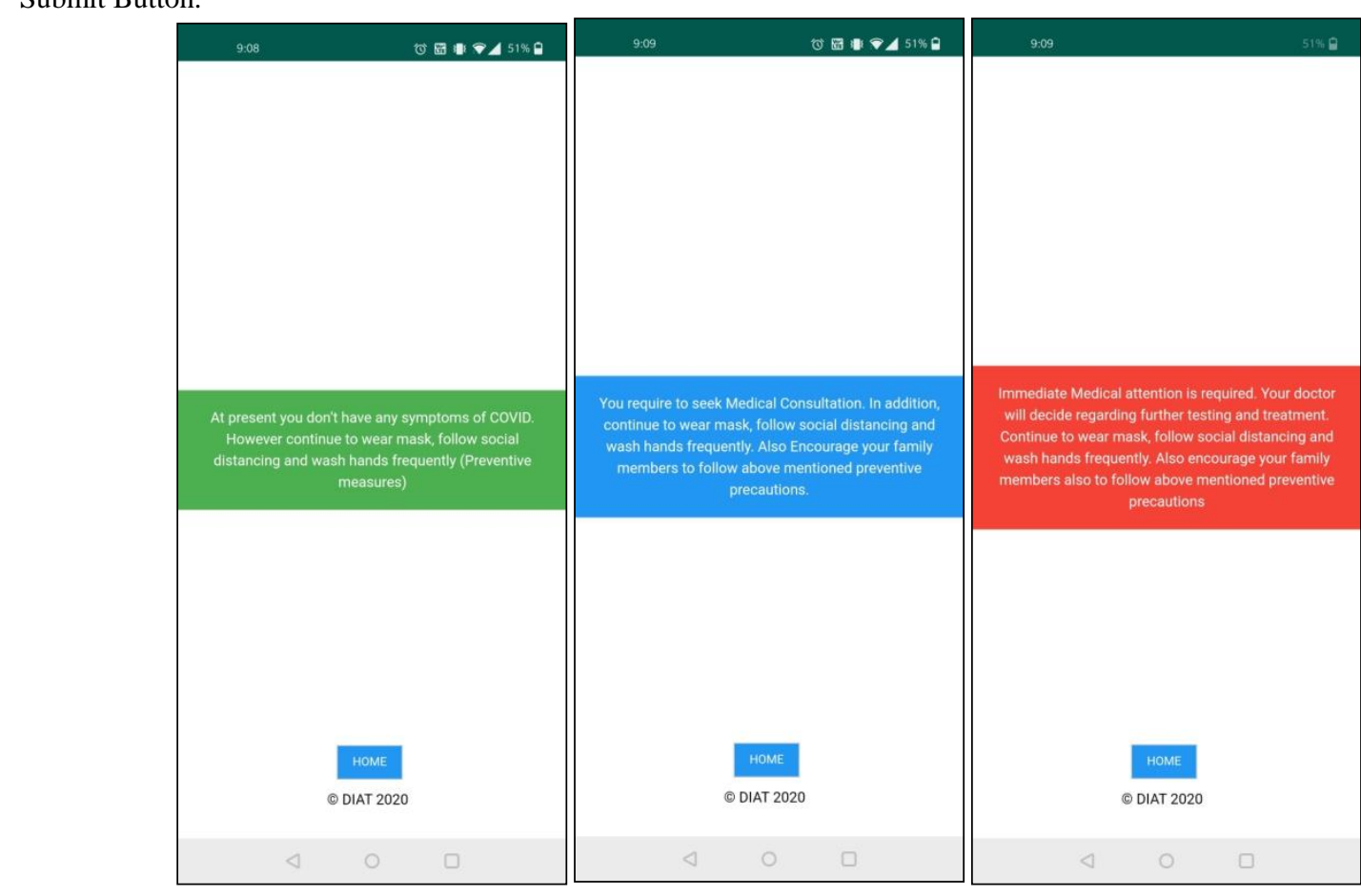

Figure 6: Mobile Phone Screen shots of colour coded out messages for the user, Green, Blue and Red
5. The output generated is color coded with following screens: (Fig 2)

6. Green code: Message for normal or asymptotic persons

7. Blue code: Message for mild infections

8. Red Code: Message for suspected infection where Doctor consultation is urgently required.

9. Application can be restarted by selecting Home button.

10. Application can be terminated easily by Phone menu. 
The ArogyaKshema App output messages are based on the inputs entered by the user. User need to be aware that any errors in input may be their sole responsibility. The usage of the ArogyaKshema App is monitored through google analytics. The number of users, the country of access, the timings and mode are recorded and displayed as follows. The analytics indicate the growing number of users and increasing popularity of the toolkit.
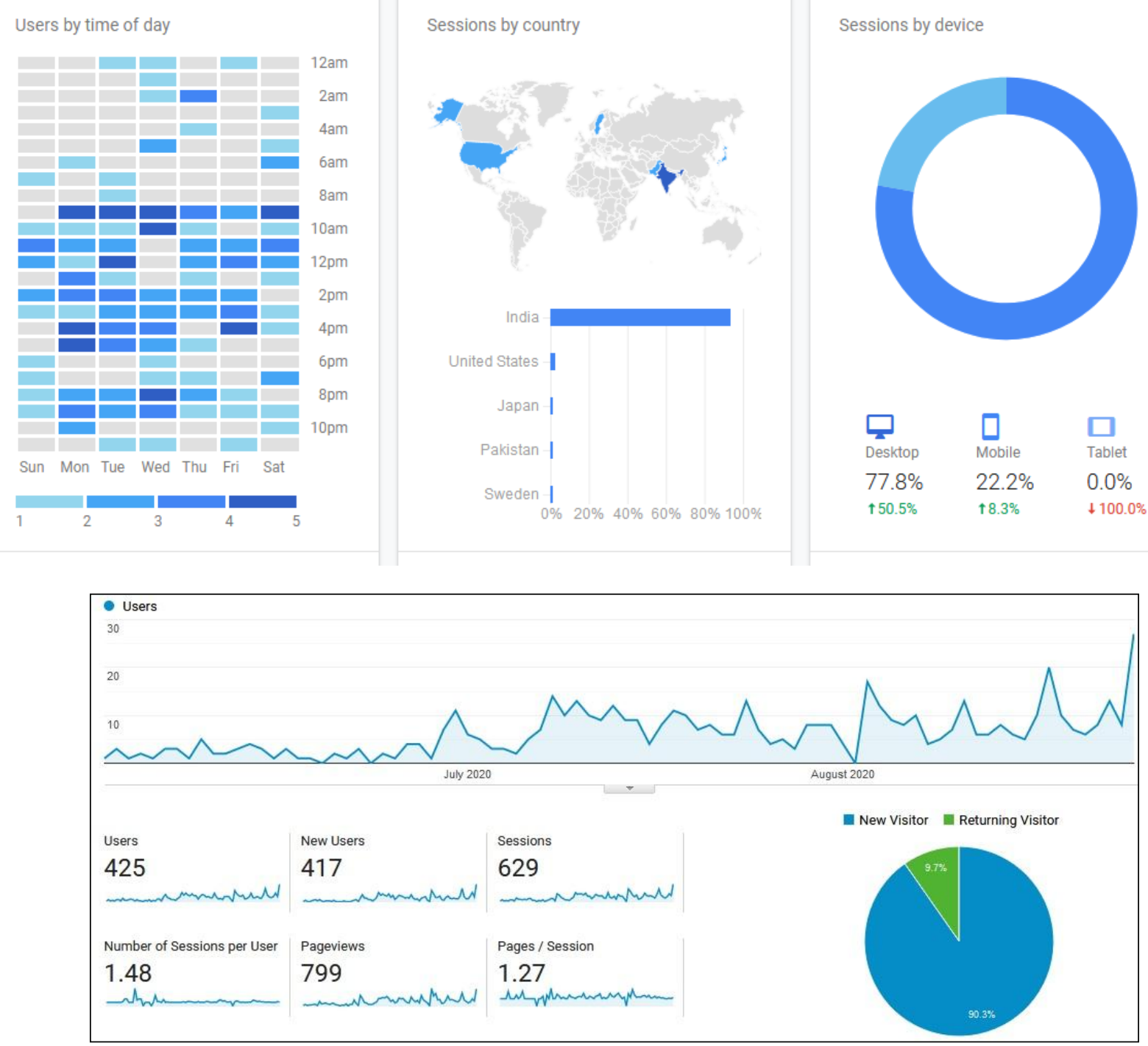

Figure 7: Usage statistics of ArogyaKshema

\section{SUMMARY AND CONCLUSIONS}

ArogyaKshema App is for COVID-19 Infection Self Assessment Test and plays an important role in containing and controlling the spread of COVID-19 Infection. The ArogyaKshema App has been tested extensively and is gaining popularity. The ArogyaKshema app is secure and maintains strict privacy of the user. The app presents instantaneous results enabling the users to assess themselves in real time. The app is portable, lightweight, robust solution with extensive support for Indian and Foreign languages. The app augments the various testing and diagnostic tools for COVID-19 Infection.

\section{ACKNOWLEDGEMENTS}

ArogyaKshema App was developed as a part DIAT Institutional funded Project. Authors acknowledge the medical advise from Medical Experts Dr Jitendra Ingole, Dr Madhura, Dr Srilatha Bhargava, Dr Nathan Grills. The ArogyaKshema App translation tasks have been supported by DIAT COVID19 Warriors team consisting of students and faculty members.

\section{REFERENCES}

[1] WHO COVID-19 Disease Dashboard https://covid19.who.int/ (Last accessed 16th July 2020)

[2] Android Studio, https://developer.android.com/studio (Last Accessed 25th July 2020)

[3] COVID-19 Vaccination, Wikipedia: https://en.wikipedia.org/wiki/COVID-19_vaccine (last accessed 16th July 2020)

[4] COVID-19 Pandemic, Wikipedia: https://en.wikipedia.org/wiki/COVID-19_pandemic (last accessed 16th July 2020)

[5] Arogya Setu App: https://www.mygov.in/aarogya-setuapp/ (Last accessed 16th July 2020)

[6] C19-SVT: COVID 19 Social Vaccine Toolkit, https://sway.office.com/yogOWXNvUApHFfPF (Last accessed 16th July 2020)

[7] ArogyaKshema App : COVID 19 Infection Self 
Assessment

Tool:

http://14.139.111.180/ArogyaKshema/Arogyakshema.ht $\mathrm{ml}$ ( last accessed 16th July 2020)

[8] Ahmad S, Hafeez A, Siddqui SA, Ahmad M, Mishra S. A Review of COVID-19 (Coronavirus Disease-2019) Diagnosis, Treatments and Prevention. EJMO 2020;4(2):116-125. DOI: 10.14744/ejmo.2020.90853

[9] Nicholas C Grassly, Marga Pons-Salort, Edward PK Parker, Peter J White et al. Role of testing in COIVD-19 control. Imperial College London (23-04-2020), doi: https://doi.org/10.25561/78439.

[10] J. Hadaya et al, Testing Individuals for Corona Virus Disease (COVID), JAMA May 19, 2020 Volume 323, Number 19, doi:10.1001/jama.2020.5388

[11] Yi-Wei Tang et al, The Laboratory Diagnosis of COVID19 Infection: Current Issues and Challenges, J. Clin. Microbiol. April 2020, doi:10.1128/JCM.00512-20

[12] ICMR, Strategy for COVID-19 testing in India (Version 5 , dated 18/05/2020)

[13] T. Zitek, The Appropriate Use of Testing for COVID-19, Western Journal of Emergency Medicine, April 2020, DOI: $10.5811 /$ westjem.2020.4.47370

[14] Andriod https://developer.android.com/docs (Last Accessed 4/8/2020)

[15] Android web view: https://developer.android.com/reference/android/webkit/ WebView (Last Accessed 4/8/2020)

[16] Wikipedia on COVID 19 Testing: https://en.wikipedia.org/wiki/COVID-19_testing (last accessed 4/8/2020)

\section{AUTHOR'S PROFILE}

Dr. CRS Kumar is currently Professor in the Computer Science and Engineering Department, Defence Institute of Advanced Technology (DIAT), DRDO, Ministry of Defence. $\mathrm{He}$ has received $\mathrm{PhD}$, MTech., MBA and B.E. degrees from reputed Universities/Institutes. His areas of interest are in Cyber Security, Network Security, Fault Tolerant Computing, Game Theory, Wireless Networking. He is a Fellow of IETE, Fellow of Institution of Engineers, Senior Member of IEEE, Chartered Engineer (Institution of Engineers) and Distinguished Visitor Program (DVP) Speaker of IEEE Computer Society, Lean Six Sigma Green Belt.
Dr Kumar brings with him rich industry, research and academic experience. Dr Kumar has worked in leading MNCs such as Philips, Infineon, L\&T Infotech in senior positions. He has visited several countries such as Australia, Germany, France, Netherlands, USA, UK, HK for work/conference participation. Dr Kumar has won several prizes for innovation and quality. Dr Kumar is member of DIAT Academic council, Board of Management (BoM) and AICTE-INAE Steering Committee. He is currently supervising $7 \mathrm{PhD}$ students and 6 Master's students. He is recipient of several awards including "Best Individual for Creating Cyber Security Awareness "at CSI-IT2020 Annual Technology Conference 2017, held at IIT Mumbai and "Microsoft Innovative Educator Expert (MIE Expert) Project Showcase Award" at Microsoft Edu Days.

T Pradeep Pai is currently working as Deputy Manager in the software division of Bharat Electronics Limited, Government of India, Ministry of Defence. He is also pursuing his master's degree in artificial intelligence at Defence Institute of Advanced Technology (DIAT), DRDO, Ministry of Defence. His areas of interest are in Artificial Intelligence, Cloud computing, Cyber Security, Network Security, Web and mobile computing. He has more than 10 years of experience in design and development of enterprise grade defence applications. He is recipient of numerous research based $\mathrm{RnD}$ awards at BEL. He has filed for a patent and has published international papers.

Maj Kunal Pal has done his schooling from Army Public School, Dhaula Kuan, New Delhi. The officer has done his military training from the National Defence Academy (NDA), Khadakwasla, Pune and Indian Military Academy (IMA), Dehradun. He has got a degree of B.Sc. Computer Science and has done Post Graduate Diploma in Military Studies and Defence Management. The officer also holds a degree of B. Tech in Telecommunication \& Information Technology from Military College of Telecommunication Engineering, Mhow. He got commissioned into the Indian Army, Corps of Signals in Dec 2008 and has served in a counter-insurgency environment in North East and in a Wireless Experimental Unit in the Northern Command where he was awarded CISC Commendation in Jan 2015. A keen adventure enthusiast, who loves to fly Microlight Aircraft. He was posted as an Instructor of Power Hang Gliders at Army Adventure Nodal Centre, Mhow and is part of the Army Microlight Flying Team. The office has also completed his Masters in Cyber Security from Defence Institutes of Advanced Technology (DIAT), Pune. 